\title{
Deconstruction and the Archival Revolution: on the Relevance and Reception of Archive Fever in New Media Studies*
}

\begin{abstract}
Glavaš Zvonimir, Deconstruction and the Archival Revolution: On the Relevance and Reception of Archive Fever in New Media Studies. "Poznańskie Studia Slawistyczne" 19. Poznań 2020. Publishing House of the Poznań Society for the Advancement of the Arts and Sciences, Adam Mickiewicz University, pp. 61-76. ISSN 2084-3011.

The paper focuses on the reception of Derrida's Archive Fever among (new) media theorists and its relevance for the ongoing discussions in that academic field. Although this Derrida's text is often described as the one in which he provides a statement on the pervasive revolutionary impact of new media, its reception among media theorists remains scarce. Several media scholars that tackle the text, however, have an ambivalent stance on it: they appreciate some of Derrida's theses, but regard them largely obsolete.

The first part of the paper analyzes these critiques and argues that many of the objections on Derrida's behalf are caused by the misinterpretation of important features of the deconstructive thought. In its second part, the paper firstly deals with certain weaker points of Derrida's reflection and then proceeds to examine his insights pertinent to the problems of contemporary media theory that were neglected in earlier reception. Finally, paper reaffirms the claim about the need for a more profound exchange between the deconstruction and media studies, albeit one that would avoid the examined shortcomings.
\end{abstract}

KeYwords: Archive Fever; new media; archive; deconstruction; media studies

\section{Introduction}

Although already the jacket cover of Derrida's Archive Fever (1996) promises a work in which he "offers for the first time a major statement on the pervasive impact of electronic media, particularly e-mail," issues

*This paper has been supported by Croatian Science Foundation under the project IP-2018-01-7020 "Literary Revolutions." 
typically attracting the attention of media studies are not exactly the sole and central topic of that Derrida's complex text. Nevertheless, among Derrida scholars, Archive Fever has remained known as his rare excursion in the new media field, and that characterization is far from being entirely unjustified.

On the other hand, it is true - as Gane and Beer $(2008,75)$ and Strathausen $(2009,142)$ notice - that Derrida never attempted to develop a systematical media theory, at least in a narrower sense. ${ }^{1}$ As a matter of fact, he seldom wrote about electronic media, ${ }^{2}$ despite recognizing himself as a passionate TV consumer (cf. Derrida, Stiegler, 2002). It is thus no wonder that, unlike certain other comparable scholars (most notably Deleuze), ${ }^{3}$ Derrida's name rarely appears as a major reference in classics of the (new) media theory. This fact indubitably contributes to the rather scarce reception of Archive Fever among media theorists: the reputation it enjoys in its original scholarly domains is not perfectly matched in the neighboring field of media studies, where the text is only sporadically cited.

Certain media theorists, nonetheless, engaged in a more thorough analysis of Derrida's Archive Fever. By dedicating it more space and attention than it was the case earlier, they tried to disclose the potential usefulness of Derrida's work for the broadening of the perspective of media studies, but also to underscore what they considered various shortcomings of Archive Fever and other Derrida's media-related reflections, caused by his inadequate understanding of media theory. The curious common denominator of those readings, however, is that, on the one hand, they unanimously utterly

${ }^{1}$ Most of Derrida's work, of course, pertains to the question of media in the most general sense; that fact is - unfortunately - often overlooked in the field of media studies. However, Derrida never systematically dealt with a particular (type of) media and produced discourse typical for what is today recognized as media studies/theory.

${ }^{2}$ Besides in Archive Fever (1996), Derrida most notably dealt with media in a minor segment of Specters of Marx (1994) and in his interviews published in Ecographies of Television (Derrida, Stiegler, 2002).

${ }^{3}$ Among the theorists usually referred to as poststructuralist, Deleuze is certainly most influential in media studies. Above all, his notion of rhizome (cf. Deleuze, Guattari, 1987) was often used by media theorist to conceptualize decentered nature of new media, and his Postscript on the Societies of Control (Deleuze, 1992) is an unavoidable reference in many of the contemporary studies on new media. 
agree with Derrida on the revolutionary impact that new media have made on the structure of the modern-day archives, while on the other hand they argue that the same impact caused Derrida's theoretical perspective to become obsolete in relation to new media.

This paper will argue that the root of the aforementioned paradox lies in what we may characterize as a reciprocal deficit of understanding, albeit situated on different ontological levels. Moreover, it will try to underscore that the divergence of the two perspectives directly affects the different conceptualizations of and approaches to the archive which is undergoing presumed revolutionary change.

In its first part, the paper thus aims to show that the dismissal of Derrida's theoretical viewpoint as obsolete results from a lack of understanding of the fundamental features of deconstructivist thought, i.e. from the misunderstanding of ontological nature of Derrida's concepts such as writing and text/textuality, as well as his other related "(quasi-) concepts" (Choat, 2010, 70). It is important to note, and that matter will be addressed throughout the paper, that this misunderstanding is not an isolated problem, but the basis of further differences regarding the conceptualization of the archive.

The second part of the paper tackles two different yet interrelated issues. Firstly, it focuses on the elements of Derrida's discourse on (new) media that largely justify the objections of media scholars on his behalf, since they indicate a lack of understanding of certain specificity of new media, albeit on a different, more concrete level (ontic, so to say). Finally, the paper proceeds to examine the potential which deconstruction - especially Derrida's treatment of archive - possesses to benefit media studies; the possibility that remained out of the focus due to these reciprocal misunderstandings.

All the outlined research question will be approached from the theoretical standpoint that is overtly Derridian, although it maintains dialogue with some of the seminal studies of media theory. The close (deconstructive?) reading applied on the texts of Derrida's critics, however, will not spare certain aspects of Derrida's Archive Fever as well. 


\section{Has the archival revolution in the new media context made deconstruction obsolete?}

The rift separating media studies from dominant currents of contemporary literary theory and continental philosophy, causing discrepancies of reception of Derrida between the two of its sides, did not remain unnoticed in earlier discussions. Strathausen (2009) addresses it in his critique on Derrida's reflections on media, albeit not without contradictions. He argues that the productive interaction between deconstruction and media theory is impeded by the "significant methodological differences between the hermeneutic approach of literary studies $[\ldots]$ and the post-hermeneutic approach favored by contemporary media studies" (Strathausen, 2009, 141). In other words,

the former study the production of meaning on the textual level via a semiotic critique of linguistic signification and rhetorical structures, whereas the latter dismiss these very processes as secondary effects of the technological media and the materialities of communication that enable meaning production in the first place (Strathausen, 2009, 141).

However, on the very beginning of his text, Strathausen $(2009,140)$ points to Derrida's claim that one of the central tasks of deconstruction is "to resist the naturalizing effects of technology and the televised image;" namely the very opposite of what was previously described as the "hermeneutic approach." Indeed, if the "hermeneutic approach" implies a form of preference of signified over the signifier, then deconstruction is as far removed from it as possible. Already in his earliest writings, Derrida (2001, $353,355)$ argued against the "reduction of the structurality of structure," i.e. "reducing or deriving the signifier" in favor of the signified/referent, and that standpoint is shared by a significant part of the contemporary literary theory. On the contrary, the strong emphasis that certain currents of media studies put exclusively on the technical dimension of a medium is a form of transcendentality itself.

A somewhat simplified vision of deconstruction, closely related to analogous perspective on literary studies, is a common denominator of other objections to Derrida's understanding of media laid out in Archive Fever as well. Both Strathausen $(2009,140)$ and Gane and Beer (2008, 
$71,76)^{4}$ argue that a significant problem for the application of Derrida's concept of the archive (and deconstruction in general) on new media field is its emphasized textual nature which falls short when confronted with the multimedial character of the new media. However, they either fail to notice or simply disagree with the fact that Derrida's notions of (arche-)writing and text imply an interweaving of differential engravings and traces that cannot be reduced to the linear phonetic writing. ${ }^{5}$ As a matter of fact, in his early work Freud and the Scene of Writing, the text on which Archive Fever largely relies, Derrida explicitly notes that "at decisive moments of his itinerary" Freud recursed to metaphorical models borrowed "not from spoken language or from verbal forms, nor even from phonetic writing, but from the script which is never subject to, never exterior and posterior to, the spoken word"6 (Derrida, 2001, 249; regarding Freudian metaphors for "primary" writing; metaphors including hieroglyphics, pictographic and ideogrammatic elements, comic-like graphic usage of words etc. cf. Derrida, 2002, 262, 274).

This narrow understanding of Derrida's notions is an interesting inversion of decade-earlier connections drawn between Derrida's conceptual

${ }^{4}$ Gane and Beer $(1988,148)$ state that a "privileging of the written form" is "prevalent in Derridean" (Gane and Beer, 2008, 71) approach to archive, as well as that Derrida's perspective on new media is determined by his "textual bias" that "privileges writing [...] over all other forms of archival data" (Gane and Beer, 2008, 76). Strathausen claims that "Derrida's own philosophical project has been primarily concerned with intralinguistic relationship between speech and writing rather than with the intermedial relationship of words and images" (Strathausen, 2009, 140). However, the opposition between word and image, or writing and other forms of data, is unsustainable in light of Derrida's (arche-)writing and related concepts, since they do not discern between various forms of differential traces/engravings.

${ }^{5}$ These misunderstandings are probably the ground for a rather confusing Strathausen's statement regarding Derrida's (in)famous and often misinterpreted thesis that " $[\mathrm{t}]$ here is nothing outside of the text" (Derrida, 1997, 158), i. e. that "every referent, all reality has the structure of a differential trace, and that one cannot refer to this 'real' except in an interpretative experience." Strathausen $(2009,143)$ argues that "[m]edia theory $[\ldots]$ will readily agree with the latter part of Derrida's statement. Yet it will remain suspicious of the first - particularly if 'trace' is understood solely in semiotic-linguistic terms, which limits rather than enhances our understanding of the nexus among media, the body, and the real." It is however impossible to truly separate the two parts of Derrida's statement, and if the latter part is accepted, it automatically implies acceptance of the broader concept of the term trace.

${ }^{6}$ In other words - a lot of concepts that could be used to describe new media content as well. 
apparatus and new media which were more affirmative, albeit equally simplifying. As Aarseth $(1997,82)$ notes, many early studies on hypertext (e.g. Bolter's) “often concerned with showing how hypertext embodies the iconoclastic musing of the so-called poststructuralist movement." For some of media theorists in those years, new media finally realized Derridian blueprint of general textuality. In contrast, for several previously mentioned readers of Archive Fever, new media made it completely obsolete.

Both stances are overly reductive since Derrida's concepts in question pertain to the ontological features that are common to both new and old media. However, while the earlier stance is clearly a mistake in discerning levels of the ontic-ontological difference, the latter seems to be even more confusing. When referring to Derridian différance, Strathausen $(2009,155)$ states that he has "no difficulty accepting Derrida's ontological claim," however a moment later he contradicts it and argues that

différance is not a neutral term to refer to such otherness. It is a media-specific term culled from and referring back to the world as "seen" through language. Unless we keep this in mind, Derrida's claim becomes tautological: he registers the living presence through language, and since language is structured by différance, the living presence itself appears to be structured by différance (Strathausen, 2009, 155).

Moreover, he even claims that "Derrida underestimate[s] the ontological and epistemological challenges technological change poses to Derrida's concept of différance" (Strathausen, 2009, 156), since modern physics established the speed of light as the absolute border no discourse can transcend, which should lead to a conclusion that "telemediated real time (and a fortiori digital data storage) cannot simply be reduced to merely another "effect of différance"” (Strathausen, 2009, 156).

Such reduction of différance first to media-specifics of (conventional) text mediation, and then to a mere issue of delay in the information transfer, clearly testifies about a lack of understanding of the concept. And the issue in question is far from being of secondary importance or petty sophistic, since one of the fundaments for the reflections of Archive Fever is the deconstruction of the opposition between the lived experience/living memory and the prosthetic mechanical inscription; the apprehension of the ineradicable contamination of the lived presence by the prosthetic, mechanic, inscribed, i.e. the understanding of the work of the trace and différance. 
Not only that new media are not exempted from the differential logic of the trace (or have overcome it), but they are - as Wolfe $(2008,87)$ suggests - even a more convenient example of it, due to their more discreet structure. ${ }^{7}$ However, Wolfe is not simply forming another binarism. On the contrary, she underscores that she is not trying to say "that analog is the 'real' other of the digital that it haunts. Rather, the structure of any 'discretization', any diacritical system, is that of a 'trace' in Derrida's sense - the iterability in and through which it can function, and only can function, as a medium and archive" (Wolfe, 2008, 89). ${ }^{8}$

Moreover, the phenomenon of differrance is the very reason behind the divergence between Derrida's concept of archive and the one embraced by his new media critics. Unlike the approaches that conceive the archive as a static sum of existing documents/data, what Derrida dubs 'archive' in Archive Fever (1996) implies a result of every temporary stabilization of a differential system of traces of writing/engraving. Still, it is not limited to what is present, but rather includes the determination by the absent and the irreducible, spectral excess.

That brings us to another element, besides the spectral work of the trace, that equally characterizes archive even after its new media transformation; an element that is articulated in an etymologic-genealogical reflection at the beginning of Archive Fever. There Derrida $(1996,1)$ points to the ancient Greek term $\dot{\alpha} \rho \chi \dot{\eta}$, meaning both commencement and commandment. From it, he derives two principles inseparably at work in the archive: sequential and jussive, principles of sheer natural ordering and of an organization according to laws and rules; an opposition that reembodies the binarism between $\varphi v ́ \sigma ı \varsigma$ and $\tau \dot{\varepsilon} \chi v \eta / v o ́ \mu o \varsigma$. Moreover, in ancient

${ }^{7}$ Wolfe $(2008,87)$ refers to Ecographies of Television, in which Derrida introduces the issue of discretization already in regard with analog images (Derrida, Stiegler, 2002, 59), while Stiegler, same as Wolfe, recognizes it as property even more characteristic for digital media (Derrida, Stiegler, 2002, 148). However, they are not the only ones who notice it. In his seminal study The Language of New Media, Manovich (2002, 49 et passim) identifies five fundamental principles of new media that logically derive from one another, with numerical representation being the first, and modularity deriving immediately from it.

${ }^{8}$ In other words, ,the 'deadening' or 'derealization' typically associated with digital technologies vs. the ontological 'umbilical cord' of analog is always already in play with any form of representation, any archive, any semiosis whether of the word or the image" (Wolfe, 2008, 90). 
$\dot{\alpha} \rho \chi \varepsilon \tilde{\imath} \mathrm{ov}$, the magistrate's private house and seat which also housed public documents, Derrida (1996, 2 et passim) recognizes "a privileged topology" that institutes a hermeneutic authority, (re)establishes the law, interweaves private (secret) and public, singular and universal etc.

Derrida's genealogical excursion to antiquity has apparently confused some of his critics, prompting them to diminish relevance of his insights for archive in the age of new media. Gane and Beer (2008, 72-73), for instance, understand the privileged topology of archive in overly literal manner, suggesting that Derrida's perspective could be adjoined to those "traditional conceptions of the archive as a body of "officially' classified texts" in a dedicated centralized place, an official building, rather than to conceptions which recognize archives as "increasingly decentralized in form and are more open than ever to 'lay' access and production" (Gane and Beer, 2008, 72).

However, although Derrida used a very archaic form of the archive as his prime example, "the archontic power" with "functions of unification, identification, of classification," paired up with "consignation" - a coordination "of a single corpus in a system or a synchrony in which all the elements articulate the unity of an ideal configuration" (Derrida, 1996, 3) - is structurally equally at work in any contemporary archive as well. No matter how decentralized/distributed and interactive an archive today is, there are always certain power nodes - materially existing protocols and institutions as privileged points of recognition, selection, inscription and organization of archivable content (cf. Derrida, 1994, 78, as well as Galloway's, 2004 influential study Protocol. How Control Exists after Decentralization), and that structural necessity is metonymically associated with the historical $\dot{\alpha} \rho \chi \varepsilon \tilde{i} o v$.

This structural necessity brings into question Gane's and Beer's (2008, 82) claims that the contemporary development of new media "gives rise to a culture that creates and stores innumerable traces of itself, and from which nothing is easily excluded (reversing the logic of previous archival forms)." There is no doubt that new media in its actual historical context greatly exercise its democratizing potential, and that its structure is more suitable to democratic usage than the centralized structure of traditional mass-media; Derrida agrees with it as well. ${ }^{9}$ However, new media are not

${ }^{9}$ Derrida stated: „I believe that this technical transformation - of the telephone, of the fax machine, of television, e-mail and Internet - will have done more for what is called 
necessarily emancipatory per se. Even more important than that, no matter if certain archival media are (deemed as) emancipatory/democratic or not, the mere concept of the archive, at least in Derridian sense, implies the necessity of certain selections and exclusions to be made. ${ }^{10}$

These problematical aspects of the reception of Archive Fever are all logically connected and proceed one from another, altogether deriving from a misunderstanding not of the properties of new media, but rather of the significant elements of Derrida's thought. However, it would be unfair both to Derrida and his critics to reduce everything to a single aspect, no matter how important it seems. And by moving forward, toward issues more often problematized by media theory, we could notice examples of a diametrically opposite situation: both valid critical objections on Derrida's lack of technological savvy, as well as some of his potential contributions to ongoing discussions in media theory that have so far remained unnoticed.

\section{Reciprocal blind spots and potential for a mutual improvement of understanding}

Not every objection to the treatment of new media in Derrida's Archive Fever is based on misunderstanding or lack of insight in deconstruction. On the contrary, some of them are on target and prove that elements of superficiality can be criticized on both ends of the dialogue. Unlike the shortcomings analyzed in previous segment, Derrida's lapses generally pertain to the higher level of specificity and result partially from the

\footnotetext{
'democratization', even in countries in the East, than all the discourses on behalf on human rights, more than all the presentations of models in whose name this democratization was able to get started" (Derrida, Stiegler, 2002, 71). He later added that he believes no totalitarian regime, no matter its strength, "can survive above a certain threshold in the density of telephone network" (Derrida, Stiegler, 2002, 72). However, elsewhere he also warned on the increasing role of new media in distortion and manipulation of the public space in parliamentary democracy (cf. Derrida, 1994, 98).

${ }^{10}$ It is important to notice that the unavoidable selectivity of the archive appears on more than the one end - not only in selection and inscription of what is recognized as an event but also in its reception. Derrida refers to it by the term reappropriation, which cannot be neither non-existing nor total (Derrida, Stigler, 2002, 111).
} 
deficit of familiarity with the technology of new media, but also from an unusual lack of thoroughness in their examination. He comments on new media with quite a lightness and assurance, but in the same time seldom elaborates systematically the theses he sketches, nor he engages in a closer reading of media theory, which is altogether hardly comparable with the characteristic of his approach to literature or philosophy, and in direct contradiction with the importance deconstruction places on the materiality of signifier.

Moreover, Strathausen (2009, 147) rightfully disapproves Derrida's term teletechnology, used to designate new, but also some of the traditional media. Although the opinions of (new) media theorists about the most proper term for the object in question are not unison, and the most widespread notion of "new media" is far from being flawless (cf. Peović Vuković, 2012, 79 et passim for a concise overview of that matter), Derrida's choice is quite problematic. Not only that his usage of the term, as Strathausen points out, is rather unsystematic, occasionally encapsulating structurally different media, but also the term itself underscores only a single dimension of the designated object, namely not even a particularly distinctive one. By focusing on the distance which teletechnology surmounts, Derrida periodically disregards the differences between various media regarding the technological substratum, overlooks the question of their structure (centralized, decentralized or distributed - cf. Galloway, 2004, 11) and thus endangers the distinctiveness of the employed term to the extent that, at an occasion, under that umbrella term he even includes written letter (cf. Derrida, Stiegler, 2002, 37). ${ }^{11}$

Derrida's lack of familiarity with new media is also the most probable reason behind the privileging of e-mail as an example of the transformation of the archive they caused. Although Gane and Beer $(2008,76)$ ascribed it to a more general textual bias of Derrida's theory, which we discarded as problematic, the basic objection they raise is valid. In Poster's (1997, 201) distinction between the usage of new media which improved existing social functions and the one that shaped new social functions, which Poster

${ }^{11}$ The disregards are unintentional error; Derrida in the same time argues that one should pay attention to all the specificities of a communication situation within a given media (cf. Derrida, Stiegler, 2002, 38). 
considers the most important criteria for answering the question of what is new about new media, the e-mail surely belongs closer to the first group.

It is easy to agree with Derrida that

electronic mail today $[\ldots]$ is on the way to transforming the entire public and private space of humanity [...]. It is not only a technique, in the ordinary and limited sense of the term: at an unprecedented rhythm, in quasiinstantaneous fashion, this instrumental possibility of production, of printing, of conservation, and of destruction of the archive must inevitably be accompanied by juridical and thus political transformations (Derrida, 1996, 17).

Be that as it may, it is equally true that other new media phenomena have introduced far more radical changes to the archive, and consequently incited equally more drastic social transformations.

What is, however, very surprising in the reception of Archive Fever is the fact that these social and political dimensions of the transformations caused by new media are only marginally discussed. Yet Derrida (1996) dedicates far more attention to that topic than to the reflections on particular media and their technological substrata. As a matter of fact, he argues that

the question of a politics of the archive is our permanent orientation here [...]. This question will never be determined as one political question among others. It runs through the whole of the field and in truth determines politics from top to bottom as res publica (Derrida, 1996, 4).

The immense importance which Derrida places on the politics of archive is even better understood having in mind his claim that "the archive, as printing, writing, prosthesis, or hypomnesic technique in general is not only the place for stocking and for conserving" (Derrida, 1996, 16) of otherwise independently existing events; it is the "technical structure of the archiving archive" that "determines the structure of the archivable content even in its very coming into existence and in its relationship to the future" (Derrida, 1996, 17). However, the same blind spot in the reception of Archive Fever which caused the neglection of his immense emphasis on the politics of archive, has also contributed to the reductive understanding of that Derrida's thesis.

Scholars as Gane and Beer $(2008,75)$ and Wells $(2008,1)$ liken the above-mentioned Derrida's claim to the McLuhan's (1994) privileging 
the technical properties of media, most famously sublimed in his catchphrase that media is the message. Yet, while this comparison certainly is on point for many reasons, it is also necessary to supplement it with an important difference. In more than a few studies about new media (cf. Peović Vuković, 2012, 18, 20; Hjorth, 2011, 12-13; Gane, Beer, 2008, 39 etc.). McLuhan is considered an epitome of the reductive techno-determinism. Although Derrida's theses might seem equally techno-deterministic, the important difference lies in the absence of the firm border between the sides of the allegedly deterministic relationship.

It is true Derrida $(1996,15)$ claims that "upheavals in progress" of the archival technic affect "the very structures of the psychic apparatus," i.e. that the technical innovations introduced by new media go hand in hand not only with revolutionized segments of the public sphere but also with transformation of individual psyches. However, the question of causality between these factors is less clear than in typical techno-deterministic paradigm, since they are not discretely separable.

According to Derrida $(1996,12)$, the archive is "entrusted to the outside," as a parergonal element of the body proper (communal or individual); "but where does the outside commence? This question is the question of the archive. There are undoubtedly no others" (Derrida, 1996, 12). And it is an unanswerable question, because the reaching of what he calls the subjectile, the moment in which "the singular imprint [...] barely distinguishes from the impression" (Derrida, 1996, 99), in which archive is confused with $\dot{\alpha} \rho \chi \eta \dot{~(D e r r i d a, ~ 1996, ~ 98), ~ a n d ~ t h e ~ l i v e d ~ u n i t y ~ o f ~ t h e ~ i m p r i n t ~}$ and impression opposes to the prosthetic, mechanic, iterative inscription of the archive, is but a dream. ${ }^{12}$

This issue is already articulated by Derrida $(2001,287)$ in Freud and the Scene of Writing, where he underscores the double metaphor built on the analogy between the psyche and the archival machine; the latter at the same time being an external, inferior supplement to the finitude of the psychical organization, and the very best metaphor of its inner structure (or more than a metaphor, since the text reveals the inseparability of the

${ }^{12}$ Interestingly enough, questioning himself about the "moment proper to the archive" Derrida $(1994,26)$ reaches for a new media example - a floating text on a computer screen in the moment when the 'save' button is pressed. 
living experience, memory and prosthetic inscription). When those earlier insights are combined with what is further elaborated in Archive Fever, it becomes clear that one can also add the structure of public sphere to this indissoluble entanglement of structures of the individual psyche and archival machines.

In other words, the ballistic metaphor Lévy $(2001,3)$ mentions, of technology conceptualized as a projectile which strikes individuals and culture/society conceptualized as targets, is invalid for the description of Derrida's perspective. Although Derrida stresses the determinative effect of the archival technologies, unlike techno-determinists he does not conceptualize technology as an autonomous agent. The deconstructive perspective on this issue offers a way out of the binary opposition between the techno-deterministic and culture-centered approaches that have troubled media studies for a long time; an alternative that is not a sublation of the two sides but rather another manifestation of différance. ${ }^{13}$ However, since the critiques of Archive Fever have misunderstood the logic of différance in the first place, they have consequently omitted to notice the alternative it provides to one of the dilemmas most persistent in discussions about technology.

Moreover, Derrida's perspective on new media - in contrast to technodeterministic ones - is neither pessimist nor optimist. He notices the revolutionary change incited by new media, but he ascribes to it neither grim nor bright outcome per se. Instead, he is interested in the political potential of new archival technologies. The mentioned unattainability of the absolute ground, of $\dot{\alpha} \rho \chi \dot{\eta}$, is the fundamental prerequisite for the existence of politics whatsoever. And although this lack of transcendental anchoring point is not an innovation introduced by new media, Derrida emphasizes that they have improved its visibility and consequently have opened a new space for the subversion of various forms of grounding.

${ }^{13}$ The above-described position, that subverts the binary opposition in relation to which it is defined, matches the one that deconstruction assumes towards the binary opposition between idealism and materialism (cf. Derrida, 1981, 50), or between the approaches focused on historical and institutional context and the ones focused on discourses and concepts (cf. Derrida, 1995, 72). Those oppositions are, on the other side, both relevant to framing the discussions between techno-determinism and various semiotic or materialist cultural-oriented approaches in media theory. 
Thus he underscores that new media have enabled the going beyond the traditional conceptualization of the virtual (Derrida, 1996, 67), as well as the undermining of conventional concepts of citizenship and hospitality (Derrida, Stiegler, 2002, 36) by the significant expansion of their referents altogether a matter of crucial importance for Derrida's idea of politics. Technological transformation of the archive in the new media era has additionally emphasized those spectral characteristics of the archive that surpass the firm grounding and metaphysic of presence. Moreover, the uncertainty about the results of this transformation, paired with a hunch that they will be vast, only additionally accentuate the fact that any question about the archive, same as any question on true politics - and the question of archive is the political question par excellence - deals not so much with a past given at our disposal, as with a future to come (Derrida, 1996, 36). According to Derrida, the question of such future is never situated in the domain of calculable; it cannot be answered with an answer derived from a technological substratum or the social domain that surrounds it, although it simultaneously precedes them and follows from them. It is the question of radical undecidability, radical hope and radical investment; a matter of messianic "heterogenous to [...] any horizon of waiting as such" (Derrida, 1996, 72).

The complex and often forking argumentation of Archive Fever thus proves the relevance even of Derrida's discourse on the messianic - a discourse that initially seems like an odd addition to the constellation of media studies - to a number of issues in that field. But even more importantly, on the broader level, it (once again) confirms that the relevance of Derrida's work to media theory is far from being limited only to the explicitly media-related studies, spanning to deconstruction in general.

Revolutionary changes introduced by new media, therefore, did not as some studies suggested - make deconstructive thought obsolete, nor they enabled the "embodiment" of its theoretical models. However, for the numerous potential merits of deconstruction for media theory to further emerge to the foreground, the bilateral improvement in the reception is needed. As it was demonstrated, Derrida's reflections on archive important to new media studies derive directly from fundamental features of his thought which were often overlooked or oversimplified in earlier reception, so their further reception and application in that field remained scarce. On the other hand, for those rather general insights to become more 
operative and precise, more familiarity with media studies would be desirable than it is usually exerted by scholars dealing with deconstruction.

Steps taken forward on both ends would allow us to better understand both the scope of revolutionariness of archive transformations caused by new media, as well as structural features of the archive in general, which new media only make more (or less) noticeable. It is thus necessary to agree with Strathausen $(2009,142)$ that "a more profound exchange between deconstruction and contemporary media theory" should be a priority for both. However, since the earlier attempts of communication - despite their achievements - were marked by certain lags and bugs, it might be a good thing to go for a reboot.

\section{References}

Aarseth, E. J. (1997). Cybertext. Perspectives on Ergodic Literature. Baltimore-London: The John Hopkins University Press.

Choat, S. (2010). Marx Through Post-Structuralism. Lyotard, Derrida, Foucault, Deleuze. London-New York: Continuum. https://doi.org/10.1080/23269995.2011.10 707898.

Deleuze, G. (1992). Postscript on the Societies of Control. "October" 59, pp. 3-7.

Deleuze, G., Guattari, F. (1987). A Thousand Plateaus [1980]. Trans. B. Massumi. Minneapolis-London: The University of Minnesota Press.

Derrida, J. (1981). Positions [1972]. Trans. A. Bass. Chicago: The University of Chicago Press.

Derrida, J. (1988). Limited Inc. Trans. S. Weber, J. Mehlman. Evanston: Northwestern University Press.

Derrida, J. (1994). Specters of Marx. The State of the Debt, the Work of Mourning and the New International [1993]. Trans. P. Kamuf. London-New York: Routledge.

Derrida, J. (1995). Points [1992]. Trans. P. Kamuf et al. Stanford: Stanford University Press.

Derrida, J. (1996). Archive Fever. A Freudian Impression [1995]. Trans. Eric Prenowitz. Chicago-London: The University of Chicago Press. https://doi.org/10.2307/465144.

Derrida, J. (1997). Of Grammatology [1967]. Trans. G. Chakravorty Spivak. Baltimore-London: The John Hopkins University Press.

Derrida, J. (2001). Writing and Difference [1967]. Trans. A. Bass. London-New York: Routledge.

Derrida, J., Stiegler, B. (2002). Ecographies of Television. Filmed Interviews. Trans. J. Bajorek. Cambridge: Polity Press.

Galloway, A. R. (2004). Protocol. How Control Exists after Decentralization. Cambridge-London: MIT Press. https://doi.org/10.7551/mitpress/5658.001.0001. 
Gane, N., Beer, D. (2008). New Media. Key Concepts. Oxford-New York: Berg.

Hjorth, L. (2011). Games and Gaming. An Introduction to New Media. Oxford-New York: Berg.

Lévy, P. (2001). Cyberculture (1997). Trans. R. Bononno. Minneapolis: Minnesota Press.

Mannovich, L. (2002). The Language of New Media. Cambridge: MIT Press.

McLuhan, M. (1994). Understanding Media. The Extensions of Man [1964]. Cambridge-London: MIT Press.

Peović Vuković, K. (2012). Mediji i kultura. Ideologija medija nakon decentralizacije. Zagreb: Jesenski i Turk.

Poster, M. (1996). CyberDemocracy: Internet and the Public Sphere. In: Internet Culture. Ed. D. Porter. London-New York: Routledge, pp. 201-219.

Strathausen, C. (2009). The Philosopher's Body: Derrida and Teletechnology. "The New Centennial Review" 9/2, pp. 139-164.

Wells, K. H. (2008). Ancestral Irrepressible: Marshall McLuhan and the Future of the Archive in Derrida's Archive Fever. "Flusser Studies" 6. http://www.flusserstudies. net/archive/flusser-studies-06-may-2008. 6.10.2020.

Wolfe, C. (2008). Ecographies from my life in the bush of ghosts. "Angelaiki" 13/1, pp. 85-94. 